\title{
Like father, like son? A comparison of absolute and relative intergenerational labour income mobility in Germany and the US
}

\author{
Maximilian Stockhausen ${ }^{1}$ (D) \\ Received: 27 August 2018 / Accepted: 22 February 2021 / Published online: 8 August 2021 \\ (C) The Author(s) 2021
}

\begin{abstract}
Are children better off than their parents? This highly debated question in politics and economics is investigated by analysing the trends in absolute and relative intergenerational labour income mobility for Germany and the US. High quality panel data is used for this purpose; the SOEP for Germany and the PSID for the US. In Germany, 67\% of sons born between 1955 and 1975 earned a significantly higher real long-run labour income than their fathers. Those with fathers from the lowest earnings bracket were particularly mobile in absolute terms. In contrast, the fraction of US sons earning more than their fathers is $60 \%$ on average for the same cohorts. Their share decreased from $66 \%$ in the 1956-60 birth cohort to $48 \%$ in the 1971-75 birth cohort, while it changed very little in Germany. Overall, absolute as well as relative labour income mobility is larger in Germany than in the US. This indicates that economic growth has been distributed more broadly in Germany than in the US. While the majority of German males has been able to share in the country's rising prosperity and are better off than their fathers, US males continue to lose ground. Hence, Chetty et al. (Science 356:398-406, 2017) seem to be right when they say that the American Dream is slowly fading away.
\end{abstract}

Keywords Absolute intergenerational mobility · Inequality · Labour income distribution · Relative intergenerational mobility

JEL Classification: D63 - J62

Maximilian Stockhausen stockhausen@iwkoeln.de

1 German Economic Institute, Konrad-Adenauer-Ufer 21, 50668 Cologne, Germany 


\section{Introduction}

Is the promise of advancement and shared prosperity still alive in Germany and the United States (US)? A recent study by Chetty et al. (2017) creates some serious doubt, at least for the US. The fraction of children receiving a higher income than their parents has significantly fallen over time: $92 \%$ of children born in 1940 earned more than their parents compared to $50 \%$ in the 1984 birth cohort. They conclude that the American Dream is fading away. One major driver for this development is not low GDP growth but the unequal distribution of it. Although most indicators of economic inequality show lower levels of inequality in Germany over time, this does not need to automatically translate into a better situation in Germany regarding intergenerational income mobility (Organisation for Economic Cooperation and Development (OECD) 2015). This study is the first to analyse the development of absolute intergenerational mobility for Germany in a comparative framework with the US.

During the last decades, both countries were exposed to similar major structural changes which were characterized by increasing global competition, negative impacts of the financial and economic crisis of 2007/2008 on economic growth and public debt, and increasing digitization and automatization (industry 4.0). In addition, Germany faced enormous changes due to the German reunification process. It has undertaken fundamental reforms of the labour market and the social security system (Agenda 2010) and is facing new challenges through the deepening of the European Union. As the EU becomes more heterogeneous, it becomes increasingly difficult to form political majorities and to implement good policies for better lives. One recent example is the distribution of refugees among the EU Member States. Nevertheless, all these changes both offer opportunities for social improvement, for example, by opening up new employment opportunities across a more globalized and digitized world, but also offer risks of social decline, for example, due to potential job losses which originate from technological changes and rising global competition. In addition, the life plans of many people have changed over the last decades: Younger cohorts appear to be more individualistic and live longer on average, and the number of single-person households or the number of single parents has increased. All this affects the economic conditions of individuals and households as well as the distribution of income (Martin 2006; Peichl et al. 2012, among others). A priori, it is not clear how and to what extent the changes described have affected incomes within and between different generations. Against this background, a simple comparison of annual incomes by repeated cross-sections is not meaningful if the hypothesis to be tested is that the promise of shared prosperity still applies across generations.

The literature on absolute intergenerational income mobility is still very limited. This is mainly due to the need for long-lasting, high-quality data where parents and children can be linked. Chetty et al. (2017) exploit data from three different sources for the US and combine historical data from Census and Current Population Survey (CPS) cross-sections with panel data for recent birth cohorts from anonymized tax records. Other studies on the US use panel data from the Panel Study of Income Dynamics (PSID) and find similar patterns. Among others, Isaacs et al. (2008) show that absolute upward mobility has declined over the twentieth century. However, the period from 1947 to 1973 was characterized by an extraordinary high rate of growth, which has attenuated afterwards. This development is more pronounced for men's earnings than for family incomes. Rising female employment explains this difference to some extent. Lopoo and DeLeire (2012), Bengali and Daly (2013), and Acs et al. (2016) all find similar patterns for the US; differences appear mostly due to different income definitions and sample periods. No such studies exist for Germany yet. Hence, this paper is the first to 
calculate rates of absolute mobility for Germany and to directly compare these findings to the US using harmonized panel data.

The main findings of the study are that 1) absolute intergenerational labour income mobility is larger in Germany than in the US and 2) there are differences in the evolution of absolute mobility over time between countries. ${ }^{1}$ While the share of sons earning more than their fathers decreased from $66 \%$ in the 1956-60 birth cohort to $48 \%$ in the 1971-74 birth cohort in the US, absolute labour income mobility changed very little in Germany for the same cohorts and varies around an average of $67 \%$. In addition, relative mobility is higher in Germany, especially at the lower tail of fathers' labour income distribution. This is also reflected by a lower intergenerational labour income elasticity coefficient that is about 0.3 in Germany compared to about 0.5 in the US. However, the size of the gap depends, for example, on the treatment of zero and low-income observations (also see Schnitzlein 2016).

The rest of the paper is structured as follows: Section two describes the methods and data used to estimate absolute and relative intergenerational mobility in Germany and the US. The results are presented in section three. Detailed robustness checks are provided in the online appendix. Section four summarizes and discusses the results.

\section{Methods and data}

Measures of absolute intergenerational mobility can be applied to describe the extent of income differences between parents and their descendants at comparable points in time. According to Chetty et al. (2017), let $y_{i}^{s}$ denote the permanent labour income of son $i$ and let $y_{i}^{f}$ denote the permanent labour income of his father. The rate of absolute mobility $A$ is then the fraction of sons earning more than their fathers:

$$
A=\frac{1}{N} \sum_{i} 1\left\{y_{i}^{s} \geq y_{i}^{f}\right\}
$$

with $N$ being the number of sons. In contrast, the concept of relative income mobility measures the change in income positions between generations. Relative income mobility only takes place when the child's position in the income hierarchy of his generation changes relative to the position of his parents in their generation. Levels do not matter and improvements in the standard of living or shared prosperity measured in real GDP per capita growth are not covered. Relative mobility is estimated by transition matrices and intergenerational labour income elasticities. The latter is commonly used in the literature and can be derived from estimating

$$
\log \left(y_{i}^{s}\right)=\alpha_{s}+\beta \log \left(y_{i}^{f}\right)+\gamma C_{i}^{f}+\delta D_{i}^{s}+\varepsilon_{i}^{s},
$$

in an OLS framework. The notation is the same as above; in addition, $C_{i}^{f}$ and $D_{i}^{s}$ consist of control variables including two polynomials of fathers' and sons' age as well as the number of years in the son's labour income average. ${ }^{2}$ Standard errors are clustered at the family level. All

\footnotetext{
${ }^{1}$ All results on Germany refer to West Germany due to data limitations for East Germany that accrue mostly from the division of Germany after World War II. Germany and West Germany are used interchangeably.

${ }^{2}$ Other non-linearities along fathers' labour income distribution are not further investigated in this study, since Schnitzlein (2016) provides sufficient evidence against their importance in Germany and their limited impact in the US.
} 
estimations are based on large and long-running survey data sets. The Socio-Economic Panel (SOEP) is used for Germany and the Panel Study of Income Dynamics (PSID) for the US. The SOEP has been collected annually since 1984 on behalf of the German Institute for Economic Research Berlin (DIW). It captures a large variety of socio-economic characteristics at the individual and household level, including different types of income (Goebel et al. 2019; SOEP 2016). The PSID has been collected since 1968 on behalf of the University of Michigan. It encompasses similar information as the SOEP. Between 1968 and 1995 it was collected annually. Since 1995 it is conducted every two years (Panel Study of Income Dynamics (PSID), public use dataset 2018). Both data sets allow information from parents and children to be linked over time. The analysis is focused on labour income, which is individual gross annual earnings from work, including wages and salaries from dependent employment or selfemployment plus bonuses. All labour incomes are deflated to the base year 2010. For this purpose, the SOEP provides a historical series of consumer prices that can directly be applied to the data. The CPI-U-RS was used for the US. ${ }^{3}$ Thus, real labour incomes of fathers and sons are compared throughout the paper unless stated otherwise.

In a first-best world, we would have access to complete income histories of the whole (working age) population and, thus, lifetime incomes. Since this is just an utopia and lifetime incomes are usually not fully captured by household surveys, they have to be approximated for both parents and children. For this purpose, the existing literature recommends calculating a multi-year income average in a phase of life in which annual incomes are highly correlated with permanent or lifetime income. If incomes are averaged over multiple years at this stage, a good approximation of lifetime income and the related position in the income distribution should be obtained and life-cycle, as well as attenuation biases in mobility estimates, are reduced but not fully eliminated (Solon 1989; Haider and Solon 2006; Grawe 2006; Nybom and Stuhler 2016; Schnitzlein 2016). For Germany, Bönke et al. (2015) find that annual earnings from the mid-30s to mid-50s correlate most strongly with lifetime earnings. Therefore, there will be a focus on those years for approximating lifetime earnings.

Another major issue in approximating lifetime earnings from a limited number of annual income observations is the treatment of outliers, especially valid zero earnings observations that arise, for example, due to times of unemployment. Average and median income levels, absolute mobility rates as well as intergenerational elasticity coefficients tend to be sensitive to their inclusion since they affect the variance of income observations (Couch and Lillard 1998; Dahl and DeLeire 2008). In general, there are three alternatives to handle this problem: 1) including all zero observations, 2) defining a lower income limit as a cut-off threshold for trimming or bottom coding, and 3) dropping all zeros. The first option is associated with two problems. Zero observations might introduce large life-cycle bias. Since only a snapshot of incomes is used for approximating lifetime earnings, we could draw observations from a period in life with extraordinarily high unemployment that is not representative for the rest of the working life. Since the deviation from regular earnings to zero earnings is huge in most cases, this might distort the true earnings capacity of an individual very much and, thus, measures of absolute and relative mobility are biased. In addition, some model specifications do not allow the usage of zero income observations, for example, the log-linear specification of

\footnotetext{
${ }^{3}$ The impact of using different price indices on absolute income mobility is well documented in Chetty et al. (2017) for the US. In general, using the CPI-U-RS results in conservative mobility estimates since this index tends to overstate inflation. See the online appendix for more information on sample construction and variables used.
} 
OLS to estimate intergenerational elasticity coefficients. ${ }^{4}$ In this case, the second option might be preferable. However, defining a lower income limit faces similar problems as option one, and the choice of the lower limit is arbitrary in most cases but can have large effects on mobility estimators. The third option might reduce life-cycle biases but can also cause sample selection biases.

Nybom and Stuhler (2016) analyse the effects of such choices on life-cycle biases in detail and find significant differences. They conclude that it would be preferable to include zero and missing income observations in theory but doing so increases the vulnerability of estimates to life-cycle biases. Schnitzlein (2016) also investigates the influence of different lower income limits on estimates of intergenerational elasticity coefficients in much detail. He finds a significant influence of different lower cut-off points on the estimates: The higher the cut-off value, the higher the elasticity coefficient and, thus, the lower intergenerational mobility. Having that in mind, the main analysis is conducted excluding zero labour income observations to reduce potential life-cycle biases. In particular, all annual labour incomes below 1200 Euro (EUR) or 1200 US-Dollars (USD) are dropped. The threshold is set in accordance with a proposal by Schnitzlein (2016) and excludes implausibly small annual labour income observations. Nevertheless, the cut-off point is arbitrarily chosen, and it is not said to be the ideal cut-off value for analysing absolute income mobility. As a robustness check, the main results are also presented for different income cut-off points and for the case where valid zero labour income observations are included (see the online appendix for detailed results).

Furthermore, the main analysis is limited to father-son pairs only. Mothers and daughters are left out since they have undergone large changes in their employment behaviour and scope, especially in Germany, which would otherwise distort the results. A high rate of absolute mobility would be an expression of the changed integration of women in paid work, but not an indicator of the fulfilment or failure of the promise of prosperity. For a similar reason, the analysis of Germany focuses on West German father-son pairs only. As a result of the German reunification, there have been numerous biographical breaks and opportunities that would otherwise distort the results. Furthermore, the labour income of East German fathers could not be observed before 1990, which would further limit the investigation period and the number of observations.

Accordingly, the generation of West German fathers includes the 1928-1954 birth cohorts. Their labour incomes were directly observed in the years 1984 to 1993 in the SOEP when the fathers were between 30 and 60 years old. The generation of US fathers includes the 1925-1954 birth cohorts, everything else equal. For the calculation of permanent labour incomes, the fathers must have at least five valid income observations during this period, whereby the first income observation must be from 1984 (the reference year of the fathers). The generation of sons consists of the 1955-1975 birth cohorts in both countries. Here, the incomes are observed in the years from 2005 to 2016 in the SOEP and from 2005 to 2015 in the PSID, when the sons were aged between 30 and 55 years. The labour incomes of the sons are also averaged over at least 5 years, whereby the first income observation must be from 2005 (the reference year of the sons). The determination of a reference year ensures that the samples and the generation-specific average incomes are representative for the population in those years to the largest possible extent (Galler 1987, $296 \mathrm{ff}$.). The effects of different weighting strategies are discussed more detail in the online appendix. The fathers' reference year results from the starting year of the SOEP interviews. The same year is also applied to the US sample for reasons of comparability. The chosen year for sons takes into account

\footnotetext{
${ }^{4}$ To avoid this technical problem, zeros could be recoded to very small positive numbers. However, this does not solve the initially described problem.
} 
that the generations do not overlap in time given the specific age intervals and that the number of possible father-son pairs is maximized.

As additional robustness checks show, the choice of baseline years does not affect the qualitative results and the quantitative results are only marginally affected. ${ }^{5}$ However, the restriction that fathers and sons must have at least five valid income observations starting from the reference year could distort the results due to panel attrition, as long as panel attrition is not determined solely by random factors. Using longitudinal weights instead of cross-sectional weights does not alter the results. In fact, using longitudinal weights marginally increases absolute mobility at the lower end of the fathers' distribution and marginally decreases it at the upper tail. Reducing the observation period to 3 years, for example, and thus lowering the problem of panel attrition at the cost of potential life-cycle and attenuation biases, leads to very similar qualitative and quantitative results: Absolute income mobility at the lower end tends to increase so the main results can be regarded as conservative estimates of absolute mobility.

\section{Results}

\subsection{Descriptives}

Using the data described above, a total of 320 father-son pairs can be identified for Germany and 619 for the US (see Table 1). In Germany, fathers' average real permanent labour income amounts to 40,618 euros per year. Labour income was averaged over 9 years on average, while the mean age of fathers was 49 years. Sons' average real permanent labour income is 44,288 euros per year. Labour income was averaged over 10 years on average, around the mean age of 41. The fathers tend to be slightly older than their sons and have a lower real permanent labour income on average. In the US, fathers' average real permanent labour income amounts to 62,340 USD per year. Labour income was averaged over 9 years on average, while the mean age of fathers was 47 years. Sons' average real permanent labour income is 87,540 USD per year. Labour income was averaged over 6 years on average, around the mean age of 43 .

Again, the fathers tend to be slightly older than their sons and show a lower mean real permanent labour income on average. Due to the age differences, fathers' lifetime incomes may tend to be slightly overestimated compared to their sons, if earnings continue to rise with age. In this case, the results represent a lower bound of absolute income mobility: If the fathers' incomes are overestimated, then the fraction of sons with incomes larger than their fathers' incomes would actually be larger and is underestimated in this study. The problem would be more severe if fathers would be younger than their sons.

However, averages are only of limited information when analysing income distributions. In order to better understand what the margins of the generation-specific lifetime income distributions look like, kernel density functions are used as depicted in Fig. 1. Permanent labour income is more unequally distributed among sons than among fathers in both countries, although the change is more pronounced in the US. In addition, lifetime labour income inequality is substantially lower than cross-sectional labour income inequality that is usually used in distributive analyses. This is not a new finding, but it highlights once more that income mobility equalizes distributions over time and that age-income profiles are heterogeneous which should be kept in mind when looking at cross-sectional analyses of the income distribution (Bönke et al. 2015).

\footnotetext{
${ }^{5}$ The results are available from the author upon request.
} 


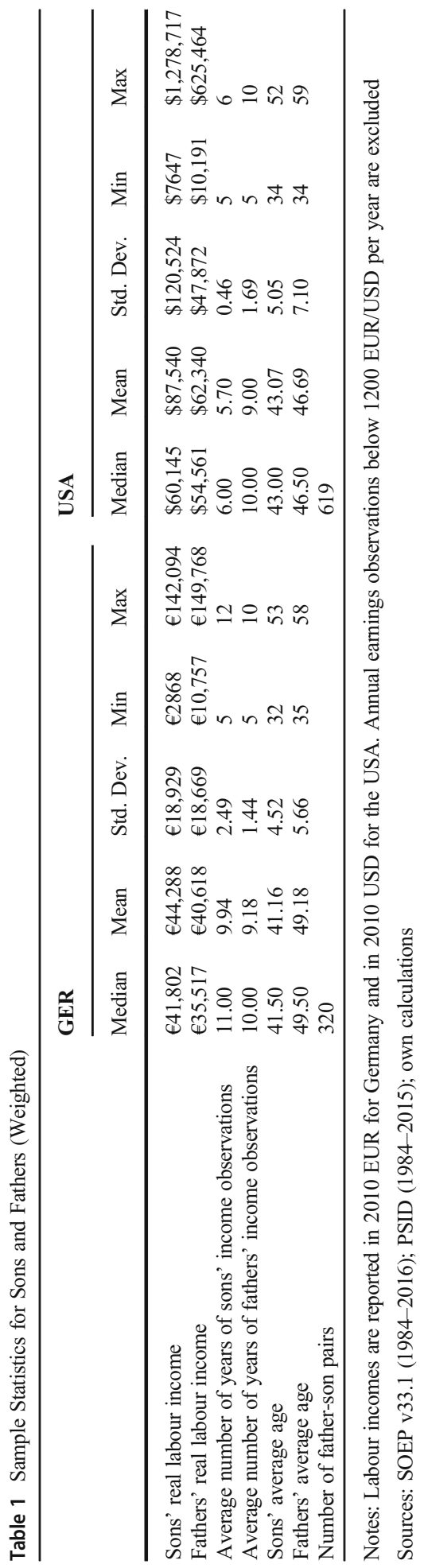



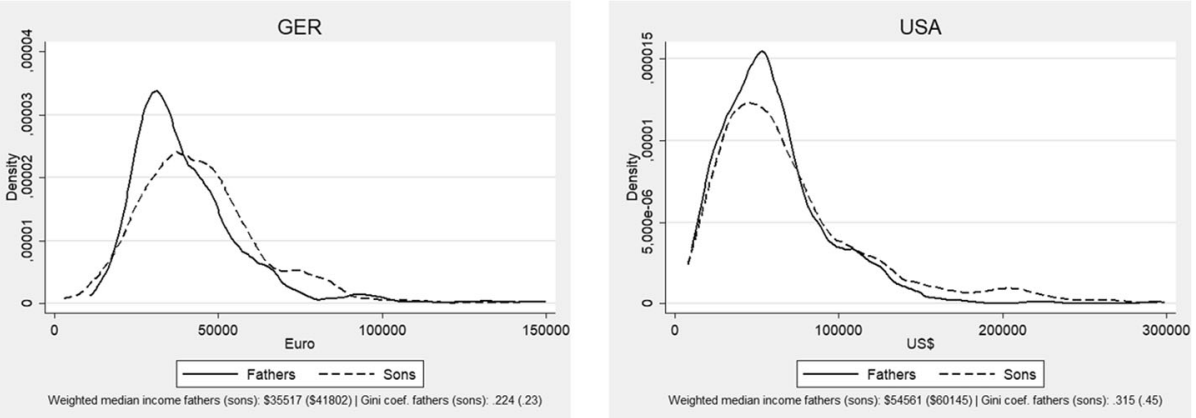

Fig. 1 Distribution of Permanent Labour Incomes. Notes: Labour incomes are reported in 2010 Euros for Germany and in 2010 US-Dollars for the USA. Annual earnings observations below 1200 EUR/USD per year are excluded. For scaling purposes, labour incomes above 300,000 USD are excluded. Sources: SOEP v33.1 (1984-2016); PSID (1984-2015); own calculations

Labour income at the tails, especially at the upper tail, is more often observed among sons. The right shift in the density function is especially pronounced in the sons' generation in Germany. This induces an improvement of the sons' generation over their fathers, which is also reflected by the increase in real median labour incomes across generations in both countries. Although the relative increase of median income is larger in the US, it comes at the cost of an increase in inequality between generations.

In the US, the generation-specific Gini coefficient rises from 0.315 for fathers to 0.450 for sons. In Germany, the Gini coefficient increases from 0.224 to 0.230 across generations. This is a remarkable difference between countries and another hint that economic growth and prosperity was shared more broadly in Germany than in the US.

Figure 2 compares the average real labour incomes of sons and fathers by labour income quartile groups. Quartile groups are formed for fathers and sons separately. The 45-degree line helps to show that average permanent labour income has increased in almost all quartile groups across generations in both countries. If a son ends up in the same quartile group as his father,
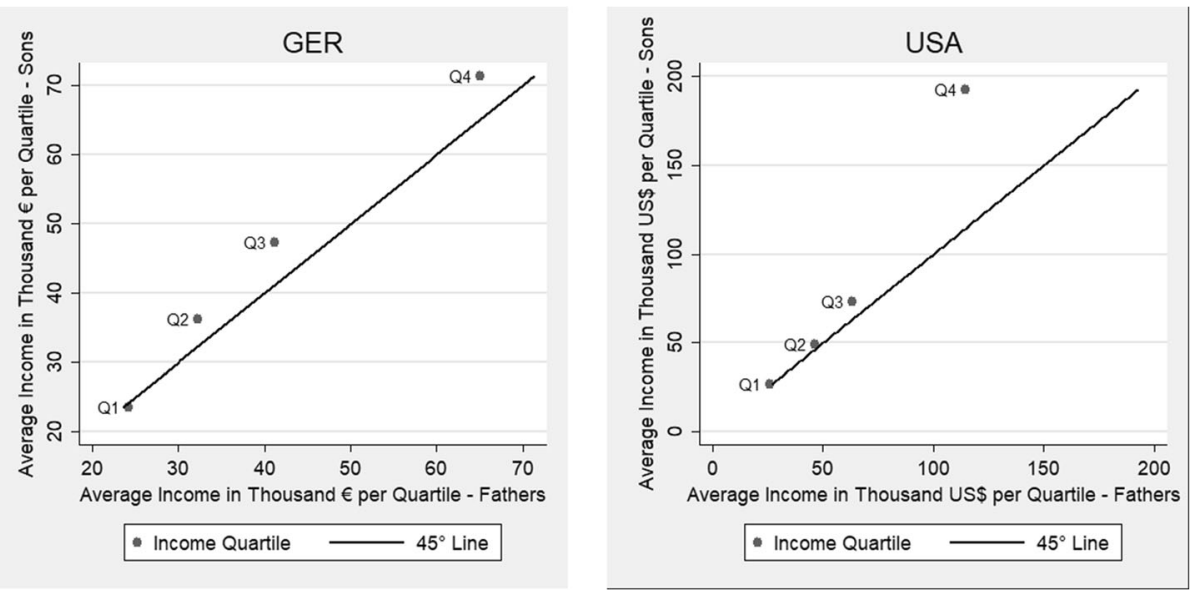

Fig. 2 Permanent Incomes by Labour Income Quartiles. Notes: Labour incomes are reported in 2010 Euros for Germany and in 2010 US-Dollars for the USA. Annual earnings observations below 1200 EUR/USD per year are excluded. Sources: SOEP v33.1 (1984-2016); PSID (1984-2015); own calculations 
he is still likely to be better off in absolute terms. The only exception is the lowest quartile group in Germany, where the average permanent labour income of sons is marginally lower compared to the fathers' generation. Overall patterns are quite similar in the US. However, the improvements at the top are disproportionality higher than in the middle, and the lower parts of the income distribution and the income distance between the third and fourth quartile group is much more pronounced in the US than in Germany. Again, this is another hint that rising economic prosperity has been more equally distributed in Germany than in the US.

\subsection{Absolute income mobility}

The positive income development between generations is reflected directly in the degree of absolute income mobility. On average, around $67.3 \%$ of sons earn a higher real permanent labour income than their fathers in Germany, compared to $59.6 \%$ in the US. Differentiating by the fathers' income quartile group in Fig. 3 reveals that the share of better paid sons is significantly larger in the lower quartiles than in the upper ones in both countries. In particular, about $92 \%$ of German sons with a father from the lowest quartile group receive a higher labour income than their fathers. It is about $35 \%$ for sons with fathers from the highest quartile group. In the US, the shares are $80 \%$ and $42 \%$, respectively. However, the most remarkable difference is found in the second quartile group: While $79 \%$ of sons in Germany receive a higher income than their fathers in this group, only $63 \%$ in the US do. Thus, absolute mobility is higher in the lower parts of the fathers' earnings distribution in Germany and higher in the upper part of the US. Shares are more similar in the third quartile group at 52\% in the US and 55\% in Germany.

Differentiation by the sons' birth cohorts, as depicted in Fig. 4, also shows that absolute mobility is quite stable over time in Germany. In the sons' 1961-65 birth cohort, about two thirds achieve a higher labour income than their fathers. In the cohort born 10 years later (1971-75), this proportion is still at $67 \%$ and in the intermediate cohort it is about $72 \%$. However, caution should be exercised when comparing the cohort results, as the number of observations in each cohort is relatively small and amounts to slightly above 100 or even less. That is why the 1956-60 birth cohort is not depicted for Germany; it is shown for the US, where the number of observations per cohort is between 100 and 200. In the US, the fraction of sons whose real labour incomes are higher than their fathers is $68 \%$ in the sons' $1956-60$ birth cohort. In the sons' $1961-65$ birth cohort, absolute labour income mobility is $64 \%$ and, thus,
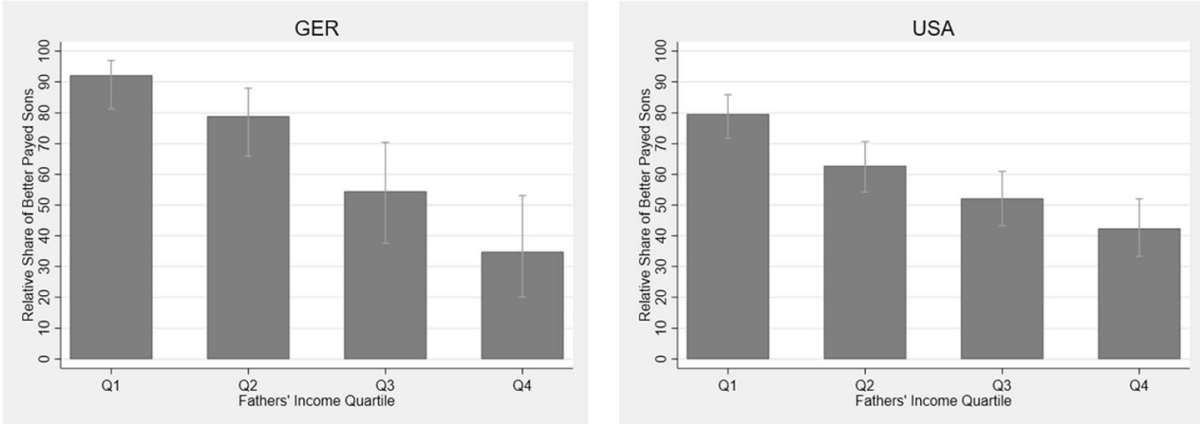

Fig. 3 Absolute Income Mobility by Fathers' Labour Income Quartile. Notes: Labour incomes are reported in 2010 Euros for Germany and in 2010 US-Dollars for the USA. Annual earnings observations below 1200 EUR/ USD per year are excluded. 95\% confidence intervals displayed at the bars were calculated by using standard errors clustered at the family level. Sources: SOEP v33.1 (1984-2016); PSID (1984-2015); own calculations 

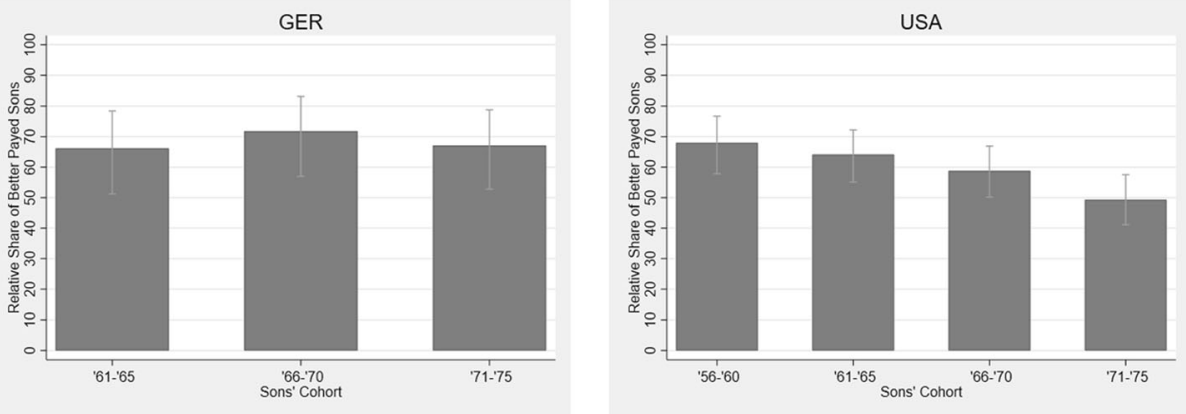

Fig. 4 Absolute Labour Income Mobility by Sons' Birth Cohort. Notes: Labour incomes are reported in 2010 Euros for Germany and in 2010 US-Dollars for the USA. Annual earnings observations below 1200 EUR/USD per year are excluded. 95\% confidence intervals displayed at the bars were calculated by using standard errors clustered at the family level. Sources: SOEP v33.1 (1984-2016); PSID (1984-2015); own calculations

about as high as in Germany. The major difference is that absolute mobility continues to decline with younger cohorts in the US, while it remains almost constant in Germany. In the sons' 1971-75 birth cohort, the fraction of sons whose real labour incomes are higher than their fathers' is about $48 \%$ in the US compared to $67 \%$ in Germany. ${ }^{6}$

This decline in the US is largely in line with the findings in Chetty et al. (2017) for similar income definitions, samples, and cohorts. However, absolute mobility estimates from the PSID tend to be slightly higher, whereas overall time trends point in the same direction: Fewer Americans are living the American Dream.

Figure 5 shows that about $92 \%$ of German sons earn more than their fathers when the father is in the lowest income quartile group (Q1) of his distribution. Moreover, absolute mobility decreases across quartile groups of fathers. The proportion of sons with a higher labour income falls to an average of $35 \%$ by the fourth. In the US, absolute mobility is smaller in the lowest quartile group but larger at the top. Only $80 \%$ of sons receive a higher labour income than their father if the latter is in the lowest quartile group. The country difference is even more pronounced in the second: $79 \%$ of sons do better than their fathers in Germany compared to $63 \%$ in the US. In contrast, absolute mobility is higher in the fourth quartile group (Q4), where the share is about $42 \%$ in the US. This is seven percentage points higher than in Germany. Overall, there is less absolute mobility at the bottom in the US than in Germany but more at the top.

Figure 5 also depicts the specific scope or intensity of sons' gains against their fathers. About $70 \%$ of sons with fathers in the lowest quartile group earned at least $10 \%$ more than their fathers in Germany. This decreases, as before, on moving to higher quartile groups. It is also noteworthy that still $48 \%$ of sons of the lowest quartile group fathers manage to earn at least $50 \%$ more than their fathers. In the top group, this share is only about $5 \%$. In the US, about $75 \%$ of sons with fathers in the lowest quartile group earned at least $10 \%$ more than their

\footnotetext{
${ }^{6}$ Different trends in absolute labour income mobility between Germany and the US may be due to the fact that educational expansion in the US took place earlier than in Germany. The sons' birth cohorts considered here are those that encompass sons who particularly benefited from educational expansion in Germany. To observe another birth cohort of sons (1967-1980) in both countries and to check whether the downward trend in absolute mobility has just started later in Germany, the base year restriction is loosened in a robustness check (see online appendix). Actually, there is slight evidence that this could be the case. However, uncertainty is high and the differences are not statistically significant at the $95 \%$ level, since only 44 observations are gained for this new birth cohort. In contrast, the rate of absolute mobility tends to be higher, again, for the 1976-1980 birth cohort in the US. This result is based on 60 observations and should therefore treated with great caution, too.
} 

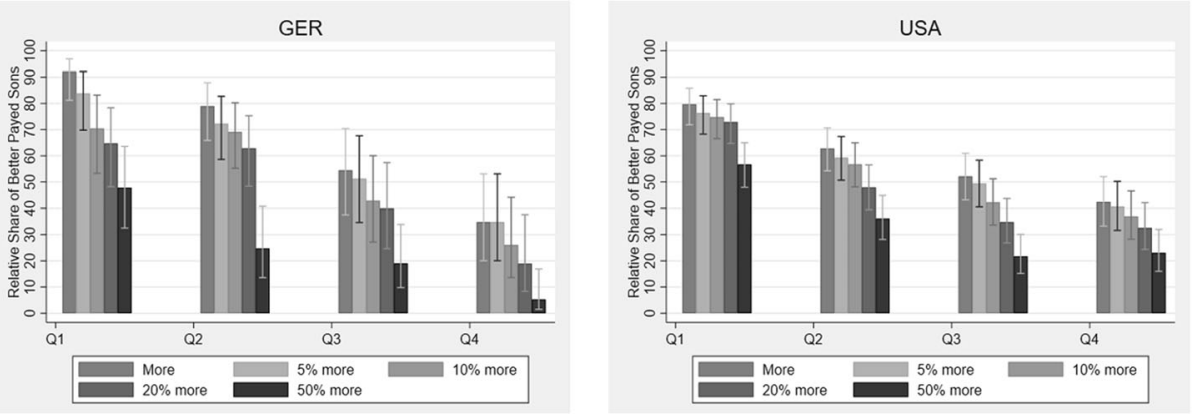

Fig. 5 Scope of Absolute Labour Income Mobility by Fathers' Labour Income Quartile. Notes: Labour incomes are reported in 2010 Euros for Germany and in 2010 US-Dollars for the USA. Annual earnings observations below 1200 EUR/USD per year are excluded. 95\% confidence intervals displayed at the bars were calculated by using standard errors clustered at the family level. Sources: SOEP v33.1 (1984-2016); PSID (1984-2015); own calculations

fathers. This is five percentage points more than in Germany. The difference is even more pronounced in the top group: about $22 \%$ of sons earn at least $50 \%$ more than their top-group fathers, compared to $5 \%$ in Germany as mentioned before. Hence, there are some remarkable differences at the tails of the distribution and in the extent of generational income gains. If American sons can do better than their fathers, they gain much more than their German counterparts. Accordingly, the share of sons earning 50\% or more is substantially higher in the US across all quartile groups of the fathers' distribution. This is in line with the previous finding that labour income is more unequally distributed in the US in both generations.

\subsection{Relative income mobility}

In this section, the discussion of differences in absolute income mobility is extended by a comparison of cross-country differences in relative income mobility, i.e. changes in the income hierarchy across generations. Hence, measures of relative income mobility, which are better indicators of equal opportunities, are examined. Figure 6 shows the relative share of sons who end up in the same, higher, or lower quartile group as their fathers. This takes into account whether a son could improve his income position towards the position of his father. In Germany, 34\% of the sons with fathers from the lowest quartile group remain in the same group. At the top (Q4), it is $46 \%$ of the sons. The same share is $28 \%$ and $16 \%$ for sons of the second and third quartile group fathers, respectively. At the same time, $66 \%$ of the sons from the lowest quartile group of the fathers manage to rise to a higher group. It is $44 \%$ for the second and $37 \%$ for the third quartile group. It is not possible to move up from the top group by construction. So, this share is $0 \%$. Similarly, downward mobility is not possible from the lowest group of fathers. Despite this, $28 \%$ of the sons with fathers from the second quartile group earn less than their fathers. By the top group, this rises to 54\%. In the US, every second son remains in the lowest quartile group if his father was in the same group. This share decreases to about $30 \%$ in the third and rises to $46 \%$ in the top group. Accordingly, relative labour income mobility is substantially larger at the bottom of the fathers' distribution in Germany than in the US and similar at the top.

In addition, the results also illustrate that relative mobility works both ways, and there are not only winners. However, the consideration of absolute mobility has shown that losses are 
GER

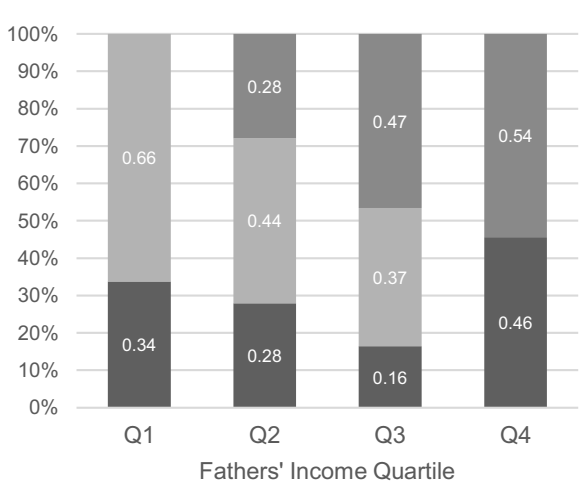

- No Mobility $\square$ Upward Mobility $\square$ Downward Mobility
USA

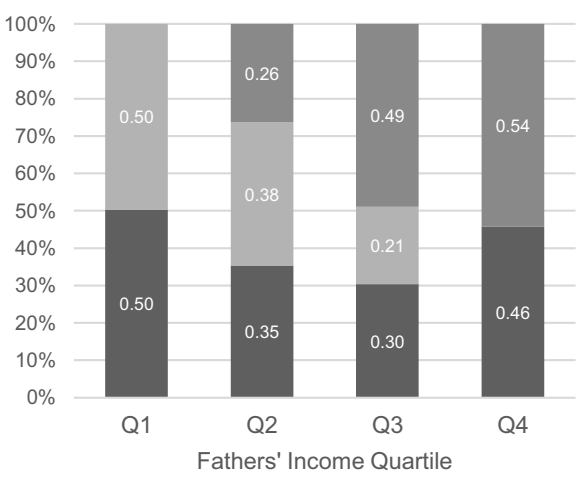

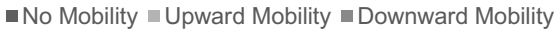

Fig. 6 Income Transition Matrix of Sons by Fathers' Labour Income Quartile. Notes: Labour incomes are reported in 2010 Euros for Germany and in 2010 US-Dollars for the USA. Annual earnings observations below 1200 EUR/USD per year are excluded. Sources: SOEP v33.1 (1984-2016); PSID (1984-2015); own calculations

often only relative ones within a generation and there are fewer absolute losses against the parents' generation. The results on relative income mobility, thus, support the outcomes on absolute mobility, which showed that the majority of sons could improve against their fathers. Even within their own generation, many sons were able to do better. This is especially true for persons with fathers from the lower part of the labour income distribution, especially in Germany.

Next, the elasticity coefficients of labour incomes $(\beta)$ shown in Table 2 can be used to answer the question of how large the general relationship between the (logarithmic) labour incomes of fathers and their sons is. The larger the reported coefficient, the stronger the relationship between the labour income of the two generations and the lower relative intergenerational income mobility. In Germany, the estimated elasticity coefficient is approximately 0.30 , compared to 0.48 in the US. The results on labour income mobility are very close to the latest results presented in Schnitzlein (2016) and Corak $(2006,2017)$.

As Schnitzlein (2016) comprehensively discusses, the results are especially sensitive to the choice of the lower cut-off value. ${ }^{7}$ This finding can be confirmed and is discussed in more detail in the online appendix. Nevertheless, the qualitative results do not change and it remains a normative question where to cut the data off, but the effects should be kept in mind since the results can differ a lot and the direction of the effect is not clear a priori. Using the "preferred" IGE coefficient of 0.32 for Germany from Corak (2006, 2017), Germany takes a middle position in the ranking of relative intergenerational earnings mobility in a broader international comparison and is ranked between Sweden (0.27) and France (0.41). Although relative mobility in Germany is lower than in the Scandinavian countries (Denmark: 0.15, Norway: $0.17)$, it is significantly higher than in the US (0.47) or the United Kingdom (0.50).

However, recent OECD findings on intergenerational mobility have cast some doubt on the existing country ranking to date (Organisation for Economic Cooperation and Development

\footnotetext{
${ }^{7}$ The treatment of imputed values is also an important issue, which is not further discussed in this paper. However, imputed labour income values are used for the analyses as provided by the SOEP and PSID (see the online appendix for more information on the variable used).
} 
Table 2 Relative Labour Income Mobility

\begin{tabular}{lll}
\hline & Sons & \\
\cline { 2 - 3 } & GER & USA \\
\hline$\beta$ & $0.299 * * *$ & $0.483^{* * *}$ \\
Standard Error & 0.073 & 0.053 \\
Controls & Yes & Yes \\
$\mathrm{R}^{2}$ & 0.083 & 0.213 \\
\#Observations & 320 & 619 \\
\hline
\end{tabular}

Notes: Standard errors are clustered at the family level. Control variables include the number of years in sons' income average and two polynomials of mean age for fathers and sons. Annual earnings observations below 1200 EUR/USD per year are excluded. Labour incomes are reported in 2010 Euros for Germany and in 2010 USDollars for the USA

$* p<0.05, * * p<0.01, * * * p<0.001$

Sources: SOEP v33.1 (1984-2016); PSID (1984-2015); own calculations

(OECD) 2018). For example, they find that relative income mobility in Germany is lower than in the US. Although Schnitzlein (2016) shows that under certain conditions relative income mobility in Germany is close to that in the US, in his analysis labour income mobility in Germany is still higher than in the US. The reason for the unexpected result of the OECD is that they calculate intergenerational mobility exclusively for dependent employees and exclude the self-employed from the main analysis. This unusual approach, which is not further justified, was criticised by several researchers (Hufe et al. 2018; Stockhausen 2018). At the same time, it shows the importance of sample restrictions, which should always be made explicit, and it raises the question - that needs to be examined in more detail in future research, but remains a challenge due to limited data - why self-employment is such a decisive factor for intergenerational mobility in Germany and not in most other industrialized countries.

Finally, Table 3 shows the results of cross-tabulating information on absolute and relative labour income mobility. This enables us to answer the question to what extent absolute and relative mobility are related. The combination of both measures reveals that about $56 \%$ of sons in Germany were able to increase their labour income above the level of their fathers and could also climb the income ladder by at least one income quartile group in their generation. If sons lost in absolute terms against their fathers, about $85 \%$ also lost in relative terms. In the US, the patterns are quite similar. Of sons who earned more than their fathers, about $52 \%$ moved up the income ladder by at least one quartile group. Since the US is less mobile in both directions

Table 3 Cross-tabulation of Absolute and Relative Labour Income Mobility (Share in per cent)

\begin{tabular}{|c|c|c|c|c|c|}
\hline \multicolumn{2}{|c|}{ Panel A: Germany } & \multicolumn{4}{|c|}{ Relative Mobility } \\
\hline & & Upward & No & Downward & Total \\
\hline Absolute & Upward & 55.99 & 40.23 & 3.78 & 100 \\
\hline Mobility & Downward & 0.00 & 15.10 & 84.90 & 100 \\
\hline \multirow{2}{*}{\multicolumn{2}{|c|}{ Panel B: USA }} & \multicolumn{4}{|c|}{ Relative Mobility } \\
\hline & & Upward & No & Downward & Total \\
\hline Absolute & Upward & 52.36 & 45.46 & 2.18 & 100 \\
\hline Mobility & Downward & 0.00 & 30.62 & 69.38 & 100 \\
\hline
\end{tabular}

Notes: Labour incomes are reported in 2010 Euros for Germany and in 2010 US-Dollars for the USA. Annual earnings observations below 1200 EUR/USD per year are excluded

Sources: SOEP v33.1 (1984-2016); PSID (1984-2015); own calculations 
than Germany, it can also be shown that fewer sons move down the income ladder (relative mobility) if they lost against their fathers in absolute terms: The share is about $70 \%$ and, thus, 15 percentage points lower than in Germany.

\subsection{Robustness checks}

Comprehensive robustness checks in the online appendix show that the structural differences between Germany and the US remain largely unchanged if key parameters in the estimation of absolute and relative labour income mobility are varied. Absolute mobility tends to increase with a higher cut-off value across cohorts and along the fathers' labour income distribution, such that the results presented in the main section tend to be a relatively conservative estimates of absolute mobility. Despite this, relative mobility decreases with an increasing cut-off value in Germany, while it shows a u-shape pattern in the US with values ranging between 0.483 and 0.448. With no lower cut-off thresholds, the elasticity coefficients are downward biased against zero in both countries. The effect is more pronounced in the US. In this case, the estimated coefficients are close to 0.230 . Hence, sample selection is an important issue and the treatment of small values should always be made explicit.

Non-random panel attrition is also a problem in longitudinal studies and is addressed in this paper by using cross-sectional weights combined with a base year age restriction for fathers and son. If no weights are used in the analyses at all, absolute income mobility remains almost unchanged in the US and tends to slightly decrease in Germany, especially for sons with fathers from the upper tail of the labour income distribution and for younger cohorts. Using longitudinal weights does not alter the results either as described before at the end of section 2 . However, the weights provided in the respective panel studies were not constructed for the specific use in intergenerational mobility analyses and it is not perfectly clear, whether their use provides better estimates.

Changing the reference base year restriction to a simple age restriction increases the number of observed father and son pairs c.p. such that an additional birth cohort can be analysed in both countries covering sons born between 1976 and 1980. Although absolute income mobility tends to be slightly lower in the latest birth cohort (1976-80) in Germany, it is still not significantly smaller compared with the oldest cohort. At the same time, absolute mobility tends to rise again for the latest birth cohort (1976-80) in the US and is statistically not different from the oldest cohort of sons. However, the number of observed father-son pairs is very small for the additional cohorts: 44 observations in Germany and 60 in the US. Thus, the results should be treated with caution. Furthermore, the elasticity coefficient of relative labour income increases from 0.299 to 0.315 in Germany, while it decreases from 0.483 to 0.414 in the US such that general qualitative findings remain unchanged.

\section{Summary and discussion}

Social inequalities are complex and multidimensional. What makes a good life and what is fair can be judged very differently. The same applies to social mobility, which in economics usually means the relationship between the income of parents and their children. Ultimately, it's about the ideal that children should do better than their parents. Therefore, the degree of absolute and relative income mobility across generations is of great interest and was investigated in this paper. 
It turned out that about $67 \%$ of sons born between 1955 and 1975 in (West) Germany earned a real long-run labour income higher than their fathers. The same share is about $60 \%$ in the US. Those with fathers in the lowest earnings groups were particularly successful in improving their status in both countries. However, absolute mobility is higher in the lower part of fathers' labour income distribution in Germany and slightly higher in the upper part in the US. Another important difference between the two countries is that absolute mobility is constant across sons' cohorts in (West) Germany while it has decreased in the US. The results for the US are, hence, largely in line with comparable findings in Chetty et al. (2017), which cover an even longer time period. They find a remarkable decline in absolute labour income mobility across time: About $92 \%$ of sons born in 1940 earned more than their fathers compared to about $50 \%$ for sons born in 1984. This gives them a good reason to say that the American Dream is fading away. According to these findings, in combination with the findings on relative labour income mobility, it cannot be said that American conditions prevail in Germany since both mobility indicators show a more positive picture in Germany. Social advancement is possible to a larger extent in Germany than in the US where most of today's sons are still better off than their fathers. The qualitative results are also robust to the choice of different cut-off points and the inclusion of zero labour income observations used for approximating permanent labour incomes. Nevertheless, the quantitative results are affected by treating zeros differently, especially in the lower parts of the income distribution. The treatment of zeros should, thus, always be made explicit.

A limitation of the study is its focus on fathers and sons. There is no sufficient data on women that would allow a differentiated analysis of absolute and relative labour income mobility by employment types. This would be a necessary precondition because women have undergone marked changes in their employment behaviour and scope, especially in Germany, which could distort the results. A high rate of absolute mobility would be an expression of the changed integration of women in paid work, but not an indicator of the fulfilment or failure of the promise of prosperity. Nevertheless, results from Chetty et al. (2017) indicate for the US that the share of daughters who earn more than their fathers tends to be remarkably lower compared to sons. This is very likely to be the result of differences in working hours (part time work) and payment. The share of women working in lower paid service sectors is still larger than for men. It is likely that similar results hold for Germany. However, there is also a conversion between genders across time that should not be neglected and is another indicator of social advancement.

In any case, labour income mobility could be further increased by promoting educational mobility, especially to those with low-income parents. Labour market demands and social conditions will continue to change, for example, through digitization, and the ability to lifelong learning will become even more important. Employment biographies and incomes of people from different cohorts will be affected differently by these new challenges. It is therefore not possible at present to predict how absolute and relative intergenerational income mobility will develop in the future. The favourable economic development of the past years, however, supports the belief that the promise of social advancement and increasing prosperity that is inherently connected with the concept of a social market economy will continue to be fulfilled in the future, at least in (West) Germany.

Supplementary Information The online version contains supplementary material available at https://doi.org/ 10.1007/s10888-021-09483-w. 
Acknowledgments I am very grateful to my colleagues at the German Economic Institute as well as to Daniel Schnitzlein and the participants of the 13th International German Socio-Economic Panel User Conference in Berlin for many helpful comments and suggestions on earlier drafts of the paper. I would also like to express my sincere thanks to the anonymous reviewers and my editor in charge for many helpful comments and suggestions. Furthermore, I would like to thank Tina Krell and Regina Sager for proofreading my work. All remaining errors are in my responsibility.

Funding Open Access funding enabled and organized by Projekt DEAL. The author is employed at the German Economic Institute. He received no extra funds.

\section{Declarations}

Conflict of Interest The author declares that there is no conflict of interest.

Open Access This article is licensed under a Creative Commons Attribution 4.0 International License, which permits use, sharing, adaptation, distribution and reproduction in any medium or format, as long as you give appropriate credit to the original author(s) and the source, provide a link to the Creative Commons licence, and indicate if changes were made. The images or other third party material in this article are included in the article's Creative Commons licence, unless indicated otherwise in a credit line to the material. If material is not included in the article's Creative Commons licence and your intended use is not permitted by statutory regulation or exceeds the permitted use, you will need to obtain permission directly from the copyright holder. To view a copy of this licence, visit http://creativecommons.org/licenses/by/4.0/.

\section{References}

Acs, G., Elliott, D., Kalish, E.: What Would Substantially Increased Mobility from Poverty Look like?, Working Paper, The Urban Institute (2016)

Bengali, L., Daly, M.: U.S. Economic Mobility: The Dream and the Data, Federal Reserve Bank of San Francisco Economic Letter 06 (2013)

Bönke, T., Corneo, G., Lüthen, H.: Lifetime earnings inequality in Germany. J. Labor Econ. 33(1), 171-208 (2015)

Chetty, R., Grusky, D., Hell, M., Hendren, N., Manduca, R., Narang, J.: The fading American dream: trends in absolute income mobility since 1940. Science. 356, 398-406 (2017)

Corak, M.: Do poor children become poor adults? Lessons from a cross country comparison of generational earnings mobility. Res. Econ. Inequality. 13, 143-188 (2006)

Corak, M.: 'Inequality is the root of social evil,' or Maybe Not? Two Stories about Inequality and Public Policy, IZA Discussion Paper No. 11005, pp. 1-82 (2017)

Couch, K.A., Lillard, D.R.: Sample selection rules and the intergenerational correlation of earnings. Labour Econ. 5(3), 313-329 (1998)

Dahl, M., DeLeire, T.: The Association Between Children's Earnings And Fathers' Lifetime Earnings: Estimates Using Administrative Data, Discussion Paper No. 1342-08, Institute for Research on Poverty, University of Wisconsin-Madison (2008)

Galler, H.P.: Zur Längsschnittgewichtung des Sozio-ökonomischen Panels. In: Krupp, H.-J. (ed.), vol. 2, pp. 295-317. Lebenslagen im Wandel: Analysen 1987, Frankfurt/Main, Sozio-ökonomische Daten und Analysen für die Bundesrepublik Deutschland (1987)

Goebel, J., Grabka, M.M., Liebig, S., Kroh, M., Richter, D., Schröder, C., Schupp, J.: The German socioeconomic panel study (SOEP). Jahrbücher für Nationalökonomie und Statistik. J. Econ. Stat. 239(2), 345360 (2019)

Grawe, N.D.: Lifecycle bias in estimates of intergenerational earnings persistence. Labour Econ. 13(5), 551-570 (2006)

Haider, S., Solon, G.: Life-cycle variation in the association between current and lifetime earnings. Am. Econ. Rev. 96(4), 1308-1320 (2006)

Hufe, P., Peichl, A., Weishaar, D.: Intergenerationelle Einkommensmobilität: Schlusslicht Deutschland?, ifo Schnelldienst 71(20), 20-28 (2018) 
Isaacs, J.B., Sawhill, I., Haskins, R.: Getting ahead or losing ground: economic mobility in America, The Brookings Institution (2008)

Lopoo, L., DeLeire, T.: Pursuing the American dream: economic mobility across generations, The Pew Charitable Trusts (2012)

Martin, M.A.: Family structure and income inequality in families with children, 1976 to 2000. Demography. 43(3), 421-445 (2006)

Nybom, M., Stuhler, J.: Heterogeneous income profiles and lifecycle bias in intergenerational mobility estimation. J. Hum. Resour. 51(1), 239-268 (2016)

Organisation for Economic Cooperation and Development (OECD): In It Together: Why Less Inequality Benefits All. OECD Publishing, Paris (2015)

Organisation for Economic Cooperation and Development (OECD): A Broken Social Elevator? How to Promote Social Mobility. OECD Publishing, Paris (2018)

Panel Study of Income Dynamics (PSID), public use dataset: Produced and distributed by the Survey Research Center, Institute for Social Research. University of Michigan, Ann Arbor (2018)

Peichl, A., Pestel, N., Schneider, H.: Does size matter? The impact of changes in household structure on income distribution in Germany. Rev. Income Wealth. 58(1), 118-141 (2012)

Schnitzlein, D.D.: A New Look at Intergenerational Mobility in Germany Compared to the U.S. Rev. Income Wealth. 62(4), 650-667 (2016)

Socio-Economic Panel (SOEP): data for years 1984-2016, version 33.1, SOEP (2016). https://doi.org/10.5684/ soep.v31.1

Solon, G.: Biases in the estimation of intergenerational earnings correlations. Rev. Econ. 71, 172-174 (1989)

Stockhausen, M.: Ist der Traum vom sozialen Aufstieg in Deutschland ausgeträumt? IW-Kurzbericht 48, Köln (2018)

Publisher's note Springer Nature remains neutral with regard to jurisdictional claims in published maps and institutional affiliations. 